\title{
Impact of maternal use of asthma-controller therapy on perinatal outcomes
}

\author{
Benoit Cossette, ${ }^{1,2}$ Amélie Forget, ${ }^{1,3}$ Marie-France Beauchesne, ${ }^{1,2,4}$ Évelyne Rey, ${ }^{5,6}$ \\ Catherine Lemière, ${ }^{3,5}$ Pierre Larivée, ${ }^{4,7}$ Marie-Claude Battista, ${ }^{4,7}$ Lucie Blais ${ }^{1,3,4}$
}

\begin{abstract}
- Additional material is published online only. To view please visit the journal online (http://dx.doi.org/10.1136/ thoraxjn-2012-203122)

${ }^{1}$ Faculty of Pharmacy, Université de Montréal, Montréal, Québec, Canada ${ }^{2}$ Pharmacy Department, Centre hospitalier universitaire de Sherbrooke, Sherbrooke, Québec, Canada

${ }^{3}$ Research Center, Hôpital du Sacré-Coeur de Montréal, Montréal, Quebec, Canada ${ }^{4}$ Centre de recherche Clinique Étienne-Le Bel, Centre hospitalier universitaire de Sherbrooke, Sherbrooke, Québec, Canada

${ }^{5}$ Faculty of Medicine, Université de Montréal, Montréal, Québec, Canada

${ }^{6}$ Department of Obstetrics and Gynecology and Research Center, Centre hospitalier universitaire Ste-Justine, Montréal, Québec, Canada ${ }^{7}$ Faculty of Medicine, Université de Sherbrooke, Sherbrooke, Québec, Canada
\end{abstract}

\section{Correspondence to} Dr Lucie Blais, Faculté de pharmacie, Université de Montréal, C.P. 6128 ,

Succursale Centre-ville, Montréal, Québec, Canada H3C 3J7;

lucie.blais@umontreal.ca

Received 11 December 2012 Revised 25 February 2013 Accepted 19 March 2013 Published Online First 13 April 2013

\footnotetext{
To cite: Cossette $B$, Forget $A$, Beauchesne $M-F$, et al. Thorax 2013;68: 724-730.
}

\begin{abstract}
Background Asthma during pregnancy usually requires treatment with controller medications about which more safety information is needed. The objectives are to assess the impact of the use of long-acting $\beta_{2}$-agonists (LABAs) and the dose of inhaled corticosteroids (ICSs) during pregnancy on the prevalence of low birth weight (LBW), preterm birth (PB) and small for gestational age (SGA).
\end{abstract}

Methods A cohort of women with asthma giving birth from 1998 to 2008 was constructed from Québec (Canada) administrative databases. LBW was defined as weight $<2500 \mathrm{~g}, \mathrm{~PB}$ as delivery before 37 weeks' gestation and SGA as a birth weight below the 10th percentile. The impact of the use of LABAs and the dose of ICSs during pregnancy on the outcomes was determined with generalised-estimating-equation models. Results The cohort included 7376 pregnancies: $8.8 \%$ exposed to LABAs and $56.9 \%$ exposed to ICSs. All LABA users also received ICSs. The prevalence of LBW, PB and SGA was $7.7 \%, 9.5 \%$ and $13.5 \%$, respectively. LABA use was not found to be associated with increased prevalence of LBW (OR $0.81 ; 95 \% \mathrm{Cl} 0.58$ to 1.12 ), PB (OR $0.84 ; 95 \% \mathrm{Cl} 0.61$ to 1.15 ) or SGA (OR 0.92 ; $95 \% \mathrm{Cl} 0.70$ to 1.20$)$. Mean ICSs doses $>125 \mu \mathrm{g} /$ day (fluticasone-equivalent) were associated with a nonsignificant trend of increased LBW, PB and SGA.

Conclusions Despite the possibility of residual confounding due to uncontrolled or more severe asthma or smoking status, the use of LABA and low to moderate doses of ICSs were not associated with increased prevalence of perinatal outcomes. Additional research on higher ICSs doses is required to better evaluate their safety during pregnancy.

\section{INTRODUCTION}

Asthma is one of the most common potentially serious medical conditions encountered during pregnancy, affecting $3.7-8.4 \%$ of pregnancies in the USA. ${ }^{1}$ Current asthma treatment guidelines emphasise the importance and safety of the use of several asthma medications during pregnancy compared with the risk of poorly controlled asthma for the fetus, since uncontrolled asthma during pregnancy has been found to be associated with increased prevalence of low birth weight (LBW), preterm birth $(\mathrm{PB})$ and small for gestational age (SGA). ${ }^{2-6}$ Pregnancy-specific guidelines recommend inhaled corticosteroids (ICSs) as the first-line asthma-controller medication and long-acting $\beta_{2}$-agonists (LABAs) as an add-on therapy to treat moderate to severe asthma. ${ }^{5}$

\section{Key messages}

What is the key question?

- What is the impact of the use of long-acting $\beta_{2}$-agonists (LABAs) and the dose of inhaled corticosteroids (ICSs) during pregnancy on the prevalence of low birth weight, preterm birth, and small for gestational age?

\section{What is the bottom line?}

- The use of LABA and low to moderate doses of ICSs were not associated with increased prevalence of perinatal outcomes.

\section{Why read on?}

- Asthma during pregnancy usually requires treatment with controller medications for which this study provides new safety information on perinatal outcomes.

Safety data on the use of LABAs during pregnancy are scarce despite their increasing use due to the evidence regarding the benefits of the LABA-ICS association, the fact that a lower dose of ICS can sometimes be used to achieve asthma control with the LABA-ICS association rather than ICS monotherapy at a higher dose, and the availability of combination products (LABA-ICS association in the same inhaler). Bracken et $a l^{7}$ found no significant increased prevalence of $\mathrm{PB}$ or SGA with the use of LABAs and Clifton et $a l^{8}$ found no difference in SGA in a group receiving a combination of ICSs and LABAs compared with ICSs alone. These studies had a limited number of women exposed to LABAs during pregnancy ( $n=64$ and 9), with the possibility of an undetected increased risk $(\mathrm{OR}=1.69$ for prematurity) in the Bracken $\mathrm{et}_{\mathrm{al}}{ }^{7}$ study.

The impact of the use of ICSs by pregnant women with asthma on LBW, PB and SGA has been evaluated in several studies, with all of them reporting non-significant results. ${ }^{7-16}$ Some of the relative risks reported, however, were as high as $1.8,{ }^{10} 1216$ indicating the possibility of an undetected increased prevalence, with only two ${ }^{14} 15$ of these studies having sufficient power to detect an increase in prevalence of adverse perinatal outcomes of $50 \%$ or more. Moreover, only two of these studies considered the dose of ICS taken during pregnancy. Namazy et $a l^{14}$ found a non-significant trend between the increasing doses of ICSs and the increasing prevalence of SGA. On the other hand, 
Bakhireva $e t a l^{2}$ found no differences in the prevalence of SGA across quartiles of ICS doses.

Our study further investigated the safety of the use of LABAs and different dose categories of ICSs during pregnancy on LBW, $\mathrm{PB}$ and SGA in a large cohort of women with asthma who gave birth between 1998 and 2008 in Québec, Canada.

\section{METHODS}

\section{Data source}

Data on medication prescriptions filled in community pharmacies, outpatient medical visits, emergency-department visits, medical procedures and hospitalisations were retrieved from two administrative databases in Québec: the Régie de l'assurance-maladie du Québec and the MED-ECHO databases. Additional information on these databases can be found in the online data supplement.

\section{Study design}

A cohort of pregnancies from women with asthma and their newborns was formed from the linkage of these databases. This new cohort includes pregnancies in the years 2002-2008 not comprised in previous cohorts from our group. The cohort inclusion criteria were (1) singleton delivery (live or stillbirth) between 1998 and 2008, (2) women aged $\leq 45$ years, (3) women with $\geq$ one diagnosis of asthma (International Classification of Diseases (ICD), ICD-9 code: 493 (except 493.2) or ICD-10 code: J45) and zone prescription for an asthma medication filled in the year before or during pregnancy, and (4) women covered by the Régie de l'assurance-maladie du Québec drug-insurance plan for at least 1 year before and throughout pregnancy. If a woman contributed several pregnancies, we kept only the two most recent. Exclusion criteria included use of theophylline, cromoglycate, nedocromil or ketotifen (45 pregnancies). Pregnancies with LABA use without ICSs (20 pregnancies) were also excluded to better reflect guidelinedriven therapy.

\section{Perinatal outcomes}

LBW was defined as birth weight $<2500 \mathrm{~g}$, SGA as birth weight below the 10th percentile for gestational age and gender using Canadian standards, ${ }^{17}{ }^{18}$ and $\mathrm{PB}$ as delivery before 37 weeks' gestation.

\section{Medication exposure during pregnancy}

LABA use was categorised as (1) use or no use during pregnancy, and (2) duration of exposure: exposed during one, two or three trimesters; both measures based on data related to prescription renewals recorded in the RAMQ databases. Average daily dose of ICS (in fluticasone-propionate equivalent ${ }^{3}$ ) was measured with an algorithm based on prescription renewals that we developed and used in previous studies, ${ }^{19} 20$ and categorised as none, low: >0-62.5, > 62.5-125, >125-250; moderate: >250-500; and high doses: $>500 \mu \mathrm{g} /$ day, according to the Global Initiative for Asthma guidelines. ${ }^{3}$ The low-dose category was broken down in three groups: $>0-62.5$ likely to represent sporadic use, $62.5-125$ representing very low dose and $>125-250$, representing low dose as recommended in guidelines.

\section{Potential confounders}

Twenty risk factors of LBW, PB and SGA identified in the literature were considered as potential confounders. The severity of asthma in the year before conception was measured with an algorithm that we developed and validated, and that categorises asthma on three levels: mild, moderate or severe. ${ }^{21}$ This algorithm is mainly based on the daily ICS dose and the use of add-on therapy: LABAs, leukotriene-receptor antagonists or theophylline (not applicable for this study) over a 1 year period. The control of asthma was assessed by weekly short-acting $\mathrm{B}_{2}$-agonists use, use of oral corticosteroids and whether the women had a hospitalisation or an emergency department visit for asthma, all measured during pregnancy. Complete information on all confounding variables is available in the online data supplement. To account for the absence of smoking status in the databases, we used a method described by Schneeweiss $e t a l^{22}$ to estimate the impact of this unmeasured confounder on the observed ORs.

\section{Statistical analysis}

Descriptive statistics were used to report the characteristics of the pregnancies and the prevalence of perinatal outcomes as a function of LABA use and the ICS dose. In the main analysis, we estimated crude and adjusted ORs for LBW, PB and SGA, comparing LABA use to no use and categories of ICS doses to no use using one generalised-estimation-equation model for each outcome. A secondary analysis was done on the association between the number of trimesters (1, 2 or 3 ) with LABA use and perinatal outcomes. More information on generalised-estimation-equation models is available in the online data supplement.

\section{Ethics approval}

We obtained approval from the Commission d'accès à l'information du Québec prior to requesting and linking the information from the MED-ECHO and RAMQ databases. This study was approved by the ethics committees of Hôpital du Sacré-Coeur de Montréal and the Centre hospitalier universitaire de Sherbrooke.

\section{RESULTS}

The cohort includes 7376 pregnancies from 6199 women with asthma, aged 27.5 years on average, $80.5 \%$ living in an urban area and $56.1 \%$ receiving social assistance. In the year preceding pregnancy, 20\% had moderate or severe asthma. ${ }^{21}$ Overall, the prevalence of LBW, PB and SGA were 7.7\%, 9.5\% and $13.5 \%$, respectively. Use of LABAs was documented in $8.8 \%$ of pregnancies (salmeterol as the only LABA 69.7\%; formoterol as the only LABA $29.2 \%$; or both $1.1 \%$ ), with use increasing from $3.5 \%$ in 1999 to $13.4 \%$ in 2008 . All LABA users also received ICSs. ICSs were used in $56.9 \%$ of pregnancies (fluticasone alone $76.0 \%$; budesonide alone $14.5 \%$; other ICSs or more than one ICS during pregnancy 9.5\%). Table 1 presents the characteristics of the pregnancies per LABA use and category of ICS dose.

A higher proportion of women exposed to LABA during pregnancy had diabetes, gestational diabetes, eclampsia/preeclampsia. Also, a higher proportion of women exposed to high doses of ICS were recipients of social assistance, had chronic hypertension, diabetes, gestational diabetes, eclampsia/preeclampsia and cystic fibrosis than women exposed to low doses. Women using LABA and high-dose ICS were more likely to have moderate or severe asthma prior to pregnancy and asthma exacerbations (emergency department visit or hospitalisation for asthma, use of oral corticosteroids) during pregnancy.

Tables 2 and 3 provide the crude and adjusted ORs for the associations between asthma medications and perinatal outcomes.

The adjusted analysis indicates that LABA use was not found to be associated with an increased prevalence of any of the outcomes under study. A non-significant increasing trend in the prevalence of the three outcomes was seen with increasing doses of ICSs over $125 \mu \mathrm{g} /$ day. On the other hand, we observed no 
Table 1 Women's characteristics according to LABA use and average daily ICS* dose during pregnancy

\begin{tabular}{|c|c|c|c|c|c|c|c|c|}
\hline & \multicolumn{2}{|l|}{ LABA } & \multicolumn{6}{|l|}{ ICS* } \\
\hline & No & Yes & None & $0-62.5$ & $>62.5-125$ & $>125-250$ & $>250-500$ & $>500$ \\
\hline $\begin{array}{l}\text { Number of pregnancies } \\
\mathrm{n}(\%)\end{array}$ & 6726 & 650 & 3178 & 1652 & 1303 & 686 & 409 & 148 \\
\hline \multicolumn{9}{|l|}{ Maternal characteristics } \\
\hline \multicolumn{9}{|l|}{ Age (years) } \\
\hline$<18$ & $127(1.9)$ & $4(0.6)$ & $50(1.6)$ & $36(2.2)$ & $28(2.1)$ & $13(1.9)$ & $1(0.2)$ & $3(2.0)$ \\
\hline $18-34$ & 5747 (85.4) & $538(82.8)$ & $2756(86.7)$ & $1423(86.1)$ & $1092(83.8)$ & $575(83.8)$ & $325(79.5)$ & $114(77.0)$ \\
\hline$>34$ & $852(12.7)$ & $108(16.6)$ & $372(11.7)$ & $193(11.7)$ & $183(14.0)$ & $98(14.3)$ & $83(20.3)$ & $31(20.9)$ \\
\hline Receipt of social assistance & $3741(55.6)$ & $394(60.6)$ & $1636(51.5)$ & $979(59.3)$ & 741 (56.9) & $416(60.6)$ & $256(62.6)$ & $107(72.3)$ \\
\hline Urban residence & $5415(80.5)$ & $525(80.8)$ & $2581(81.2)$ & $1306(79.1)$ & $1043(80.0)$ & $561(81.8)$ & $335(81.9)$ & $114(77.0)$ \\
\hline \multicolumn{9}{|l|}{ Maternal chronic conditions } \\
\hline Chronic hypertension & $194(2.9)$ & $21(3.2)$ & $86(2.7)$ & $50(3.0)$ & $38(2.9)$ & $17(2.5)$ & $15(3.7)$ & $9(6.1)$ \\
\hline Diabetes mellitus & $239(3.6)$ & $31(4.8)$ & $102(3.2)$ & $66(4.0)$ & $38(2.9)$ & $34(5.0)$ & $18(4.4)$ & $12(8.1)$ \\
\hline Cystic fibrosis of the pancreas & $32(0.5)$ & $5(0.8)$ & $14(0.4)$ & $4(0.2)$ & $9(0.7)$ & $2(0.3)$ & $4(1.0)$ & $4(2.7)$ \\
\hline Antiphospholipid syndrome & $39(0.6)$ & $2(0.3)$ & $17(0.5)$ & $8(0.5)$ & $9(0.7)$ & $4(0.6)$ & $3(0.7)$ & 0 \\
\hline \multicolumn{9}{|l|}{ Pregnancy-related variables } \\
\hline Gestational diabetes & $638(9.5)$ & $94(14.5)$ & $288(9.1)$ & $157(9.5)$ & $131(10.1)$ & $76(11.1)$ & $55(13.4)$ & $25(16.9)$ \\
\hline Eclampsia/pre-eclampsia & $195(2.9)$ & $27(4.2)$ & $86(2.7)$ & $54(3.3)$ & $41(3.1)$ & $20(2.9)$ & $13(3.2)$ & $8(5.4)$ \\
\hline Anaemia & 979 (14.6) & $96(14.8)$ & $443(13.9)$ & $240(14.5)$ & $189(14.5)$ & $110(16.0)$ & $72(17.6)$ & $21(14.2)$ \\
\hline Vaginal bleeding & $893(13.3)$ & $80(12.3)$ & $439(13.8)$ & $219(13.3)$ & $169(13.0)$ & $78(11.4)$ & $54(13.2)$ & $14(9.5)$ \\
\hline Placental conditions & $264(3.9)$ & $26(4.0)$ & $129(4.1)$ & $67(4.1)$ & $42(3.2)$ & $26(3.8)$ & $20(4.9)$ & $6(4.1)$ \\
\hline Placenta abruption & 239 (3.6) & $27(4.2)$ & $113(3.6)$ & $74(4.5)$ & $39(3.0)$ & $20(2.9)$ & $18(4.4)$ & $2(1.4)$ \\
\hline \multicolumn{9}{|l|}{ Asthma-related variables } \\
\hline \multicolumn{9}{|c|}{ Severity of asthma prior to pregnancy } \\
\hline Mild & $5621(83.6)$ & $278(42.8)$ & $2888(90.9)$ & $1427(86.4)$ & $1045(80.2)$ & $404(58.9)$ & $122(29.8)$ & $13(8.8)$ \\
\hline Moderate & $816(12.1)$ & $205(31.5)$ & $254(8.0)$ & $163(9.9)$ & $191(14.7)$ & $192(28.0)$ & $178(43.5)$ & $43(29.1)$ \\
\hline Severe & $289(4.3)$ & $167(25.7)$ & $36(1.1)$ & $62(3.8)$ & $67(5.1)$ & $90(13.1)$ & $109(26.7)$ & $92(62.2)$ \\
\hline \multicolumn{9}{|l|}{ During pregnancy } \\
\hline LABA & 0 & $650(100)$ & 0 & $85(5.1)$ & $127(9.7)$ & $178(25.9)$ & $175(42.8)$ & $85(57.4)$ \\
\hline \multicolumn{9}{|l|}{ ICS* } \\
\hline None & $3178(47.3)$ & 0 & $3178(100)$ & 0 & 0 & 0 & 0 & 0 \\
\hline $0-62.5$ & $1567(23.3)$ & 85 (13.1) & 0 & $1652(100)$ & 0 & 0 & 0 & 0 \\
\hline$>62.5-125$ & $1176(17.5)$ & $127(19.5)$ & 0 & 0 & $1303(100)$ & 0 & 0 & 0 \\
\hline$>125-250$ & $508(7.6)$ & $178(27.4)$ & 0 & 0 & 0 & $686(100)$ & 0 & 0 \\
\hline$>250-500$ & $234(3.5)$ & $175(26.9)$ & 0 & 0 & 0 & 0 & $409(100)$ & 0 \\
\hline$>500$ & $63(0.9)$ & 85 (13.1) & 0 & 0 & 0 & 0 & 0 & $148(100)$ \\
\hline \multicolumn{9}{|l|}{ SABA (doses/week) } \\
\hline 0 & $2166(32.2)$ & $115(17.7)$ & 1776 (55.9) & $267(16.2)$ & 167 (12.8) & $41(6.0)$ & $27(6.6)$ & $3(2.0)$ \\
\hline$>0-3$ & $2408(35.8)$ & $120(18.5)$ & $896(28.2)$ & $972(58.8)$ & $526(40.4)$ & 93 (13.6) & $32(7.8)$ & $9(6.1)$ \\
\hline$>3$ & $2152(32.0)$ & 415 (63.8) & 506 (15.9) & $413(25.0)$ & $610(46.8)$ & $552(80.5)$ & $350(85.6)$ & 136 (91.9) \\
\hline Leukoteriene-receptor antagonists & $48(0.7)$ & $67(10.3)$ & $12(0.4)$ & $8(0.5)$ & $16(1.2)$ & $17(2.5)$ & $38(9.3)$ & $24(16.2)$ \\
\hline Oral corticosteroids & $599(8.9)$ & $165(25.4)$ & 107 (3.4) & $162(9.8)$ & $212(16.3)$ & $138(20.1)$ & $94(23.0)$ & $51(34.5)$ \\
\hline Intranasal corticosteroids & 769 (11.4) & $160(24.6)$ & $228(7.2)$ & $202(12.2)$ & $206(15.8)$ & $146(21.3)$ & $103(25.2)$ & $44(29.7)$ \\
\hline$\geq 1 \mathrm{ED}$ visit for asthma & $869(12.9)$ & $137(21.1)$ & $201(6.3)$ & $248(15.0)$ & $275(21.1)$ & $145(21.1)$ & $104(25.4)$ & $33(22.3)$ \\
\hline$\geq 1$ hospitalisation for asthma & $65(1.0)$ & $24(3.7)$ & $9(0.3)$ & $20(1.2)$ & $23(1.8)$ & $17(2.5)$ & $12(2.9)$ & $8(5.4)$ \\
\hline
\end{tabular}

*Fluticasone equivalent, $\mu \mathrm{g} /$ day.

$E D$, emergency department; ICS, inhaled corticosteroid; LABA, long-acting $B_{2}$-agonist; SABA, short-acting $B_{2}$-agonists.

significant increased prevalence of the outcomes among women exposed to doses $<125 \mu \mathrm{g} /$ day.

The secondary analysis presented in table $\mathrm{E} 1$ in the online data supplement showed that a greater number of trimesters with LABA exposure during pregnancy was not associated with increased prevalence of the perinatal outcomes.

The sensitivity analysis indicates that the impact of smoking (an unmeasured confounder) on the association between ICS doses and LABA use and LBW, PB and SGA leads to an underestimation of the true OR by a factor of $6 \%$ at the most because of the small differences in smoking prevalence between medication users and non-users. The complete results can be found in table E2 in the online data supplement.

\section{DISCUSSION}

In this cohort of pregnant women with asthma, for LABA use and ICS doses $<125 \mu \mathrm{g} /$ day we found no increased prevalence of LBW, PB and SGA, while a trend for an increased prevalence of the outcomes was seen for ICS doses above $125 \mu \mathrm{g} /$ day. The prevalence of LBW, PB and SGA, found in the present study, were higher than those observed in the general population of Québec for the year 2008 (LBW 7.6\%; PB 5.6\%; SGA 10\%). ${ }^{23}$ 
Table 2 Prevalence and crude ORs of LBW, PB and SGA according to the average daily dose of ICS* and LABA use during pregnancy

\begin{tabular}{|c|c|c|c|c|c|c|}
\hline & \multicolumn{2}{|l|}{ LBW } & \multicolumn{2}{|l|}{ PB } & \multicolumn{2}{|l|}{ SGA } \\
\hline & n (\%) & OR (95\% Cl) & n (\%) & OR $(95 \% \mathrm{Cl})$ & n (\%) & OR $(95 \% \mathrm{Cl})$ \\
\hline \multicolumn{7}{|l|}{ LABA } \\
\hline None & $515(7.7)$ & Reference & $641(9.5)$ & Reference & 895 (13.3) & Reference \\
\hline LABA & $55(8.5)$ & $1.05(0.79$ to 1.41$)$ & $63(9.7)$ & $0.99(0.75$ to 1.31$)$ & $98(15.1)$ & 1.13 (0.90 to 1.42$)$ \\
\hline \multicolumn{7}{|c|}{ Daily ICS dose ( $\mu \mathrm{g} / \mathrm{day})$} \\
\hline None & $239(7.5)$ & Reference & $305(9.6)$ & Reference & $404(12.7)$ & Reference \\
\hline$>0-62.5$ & $102(6.2)$ & 0.80 (0.63 to 1.02$)$ & $133(8.1)$ & 0.81 (0.66 to 1.00$)$ & $201(12.2)$ & 0.95 (0.79 to 1.13$)$ \\
\hline$>62.5-125$ & $106(8.1)$ & $1.10(0.87$ to 1.40$)$ & $130(10.0)$ & 1.06 (0.86 to 1.32$)$ & $190(14.6)$ & 1.18 (0.98 to 1.42$)$ \\
\hline$>125-250$ & $64(9.3)$ & 1.24 (0.93 to 1.65$)$ & $73(10.6)$ & 1.14 (0.87 to 1.49$)$ & $99(14.4)$ & 1.17 (0.92 to 1.48$)$ \\
\hline$>250-500$ & $41(10.0)$ & 1.34 (0.95 to 1.89$)$ & $45(11.0)$ & $1.20(0.87$ to 1.66$)$ & 68 (16.6) & 1.35 (1.01 to 1.79$)$ \\
\hline$>500$ & $18(12.2)$ & 1.66 (1.01 to 2.73$)$ & $18(12.2)$ & $1.13(0.65$ to 1.97$)$ & $31(20.9)$ & 1.80 (1.19 to 2.71$)$ \\
\hline
\end{tabular}

${ }^{*}$ Fluticasone equivalent, $\mu \mathrm{g} / \mathrm{day}$.

ICS, inhaled corticosteroid; LABA, long-acting $B_{2}$-agonist; LBW, low birth weight; PB, preterm birth; SGA, small for gestational age.

These results are consistent with a meta-analysis including 40 cohort studies comparing women with and without asthma, that showed significant increased risks of LBW (RR 1.46), PB (RR 1.41) and SGA (1.22). ${ }^{24}$

Our results are reassuring for the use of LABAs during pregnancy with no increase in the prevalence of the perinatal outcomes studied. The published data on LABA and LBW, PB and SGA are limited to the studies of Clifton $e t a l^{8}$ with nine exposed women and Bracken $e t a l^{7}$ with 64 exposed women. Clifton et al found decreases in birthweight centiles in women with asthma taking fluticasone and salmeterol compared with women with asthma taking budesonide. ${ }^{8}$ Bracken $e t a l^{7}$ found an adjusted OR of 0.99 (95\% CI 0.97 to 1.02) for PB and an OR of 1.00 (95\% CI 0.99 to 1.02) for intrauterine growth restriction for each additional dose of LABA taken per month during pregnancy (OR of 0.74 if women taking 30 doses per month are compared with non-users). These results are concordant with our results found in the main analysis, in which LABAs were categorised as use/no use, and in the secondary analysis, in which we considered the number of trimesters with LABA use during pregnancy. Despite the possibility of residual confounding by uncontrolled or more severe asthma that would underestimate the beneficial effect of LABA, both of our analyses revealed a trend towards a protective effect of LABA on perinatal outcomes. No protective pharmacodynamic effect of LABA on pregnancy outcomes have been demonstrated in humans, consequently, we hypothesise that the trend for a beneficial effect of LABA could possibly come from improved maternal asthma control.

The observed effects of ICS use during pregnancy on the fetus are potentially coming from different sources, and the independent impact of these sources can be difficult to disentangle. First, ICS is likely to have a positive impact on the fetus by improving maternal asthma control (and fetal oxygenation) through a reduction in lung inflammation. Similarly to the results found in our study for doses $<125 \mu \mathrm{g} / \mathrm{day}$, Murphy et $a l^{25}$ observed that women with asthma not taking an ICS had a $17 \%$ reduction in birthweight centile compared with women with asthma taking low-dose ICSs. Murphy et al postulated that the inflammatory process present in asthma reduces the activity of the placental enzyme 11 $\beta$-hydroxysteroid dehydrogenase, which metabolises corticosteroids. This resulted in significant increases in cortisol reaching the fetus and a trend for reduced fetal oestriol (a marker of fetal adrenal activity), possibly leading to impaired fetal growth. The use of low-dose ICSs, by controlling maternal asthma and inflammation, would restore normal 11 $\beta$-hydroxysteroid dehydrogenase activity and thus reduce the impact of cortisol on growth impairment. ${ }^{25}$ However, a further study by the same group did not show that ICS treatment in pregnant women with asthma results in changes in fetal oestriol concentrations, leading them to conclude that the fetal adrenal function is not susceptible to exogenous glucocorticoid inhibition. ${ }^{12}$ The ideal measure of ICS exposure would be at the fetal level, but no published reports look at the presence of fluticasone or budesonide taken by inhalation in cord blood.

Second, as shown in table 1, the use of high ICS doses could be seen as a marker of more severe and/or difficult-to-control asthma, and this may confound the association between ICS doses and perinatal outcomes, since asthma severity and uncontrolled asthma have been found to be associated with an increased prevalence of adverse perinatal outcomes in some studies. $^{2} 4$ 4 26-28 Although we adjusted for asthma severity in the year preceding pregnancy and for control of asthma during pregnancy the possibility of residual confounding persists due to the imperfect measurement of severity and control of asthma.

Finally, a dose of corticosteroids above a certain threshold may have a negative impact on the fetal adrenal function, leading to impaired fetal development. ${ }^{29}$ For ICS doses $>125 \mu \mathrm{g} /$ day, we observed a non-significant trend showing increasing prevalence of the perinatal outcomes with increasing doses. The associations observed for the highest-ICS-dose, although not statistically significant, need further attention since the ORs from the adjusted analysis range from 1.45 to 1.57 and the number of events (18 for LBW and PB, 31 for SGA) is low, possibly indicating an increased risk not detected. Similarly, Namazy et $a l^{14}$ found a non-significant increase in SGA from $5.1 \%$ in the lowest to $10.3 \%$ in the highest quartile of ICS dose. They did not, however, find a trend between ICS dose and the mean birth weight. Bakhireva et $a l^{2}$ observed no difference in the incidence of SGA or mean birth weight between quartiles of ICS doses. ${ }^{2}$ Hodyl et al,,$^{12}$ using a cut-off of $1000 \mu \mathrm{g} /$ day in beclomethasonechlorofluorocarbon equivalent (or $500 \mu \mathrm{g} /$ day fluticasoneproprionate equivalent) found no difference in abdominal circumference, umbilical-artery blood flow, or birthweight centiles between low-dose and high-dose groups. The number of ICS-exposed women in their cohort was, however, limited to 76.

Additional information on the search for the best controllermedication regimen during pregnancy is available in a recently 
Table 3 Adjusted ORs of LBW, PB and SGA related to the average daily dose of ICS and LABA use during pregnancy

\begin{tabular}{|c|c|c|c|}
\hline & LBW & PB & SGA \\
\hline & \multicolumn{3}{|l|}{ Adjusted OR* (95\% Cl) } \\
\hline LABA & $0.81(0.58$ to 1.12$)$ & 0.84 (0.61 to 1.15$)$ & $0.92(0.70$ to 1.20$)$ \\
\hline \multicolumn{4}{|l|}{ Daily ICS doset } \\
\hline None & Reference & Reference & Reference \\
\hline$>0-62.5$ & $0.70(0.53$ to 0.90$)$ & 0.77 (0.61 to 0.95$)$ & 0.91 (0.76 to 1.09$)$ \\
\hline$>62.5-125$ & 1.03 (0.79 to 1.34$)$ & 1.08 (0.87 to 1.35$)$ & $1.15(0.95$ to 1.39$)$ \\
\hline$>125-250$ & $1.18(0.83$ to 1.67$)$ & 1.23 (0.91 to 1.66$)$ & $1.12(0.87$ to 1.45$)$ \\
\hline$>250-500$ & $1.20(0.81$ to 1.78$)$ & $1.28(0.90$ to 1.82$)$ & 1.26 (0.91 to 1.76$)$ \\
\hline$>500$ & $1.57(0.86$ to 2.87$)$ & 1.45 (0.76 to 2.80$)$ & 1.50 (0.92 to 2.44$)$ \\
\hline \multicolumn{4}{|l|}{ Maternal characteristics } \\
\hline \multicolumn{4}{|l|}{ Age (years) } \\
\hline$<18$ & 1.24 (0.67 to 2.29$)$ & 1.44 (0.84 to 2.46$) \mathrm{c}$ & 1.58 (1.01 to 2.46$)$ \\
\hline $18-34$ & Reference & Reference & Reference \\
\hline$>34$ & 1.40 (1.09 to 1.79$)$ & 1.34 (1.07 to 1.67$) \mathrm{c}$ & $1.18(0.97$ to 1.44$)$ \\
\hline Receipt of social assistance & 1.80 (1.49 to 2.18$)$ & 1.49 (1.26 to 1.76$) c$ & 1.45 (1.25 to 1.67$)$ \\
\hline Rural residence & 1.35 (1.08 to 1.69$)$ & Not retained & 1.21 (1.02 to 1.44$)$ \\
\hline \multicolumn{4}{|l|}{ Maternal chronic conditions } \\
\hline Antiphospholipid syndrome & Not retained & 2.99 (1.18 to 7.55$)$ & Not retained \\
\hline \multicolumn{4}{|l|}{ Pregnancy-related variables } \\
\hline Gestational diabetes & 0.70 (0.50 to 0.97$) c$ & Not retained & 0.63 (0.49 to 0.81$)$ \\
\hline Eclampsia/pre-eclampsia & 3.75 (2.65 to 5.32$)$ & 3.34 (2.38 to 4.68$) c$ & 1.68 (1.19 to 2.37$)$ \\
\hline Anaemia & Not retained & Not retained & 0.60 (0.48 to 0.75$)$ \\
\hline Fetal-maternal haemorrhage & $3.83(1.30$ to 11.3$) \mathrm{c}$ & 3.59 (1.10 to 11.75$)$ & Not retained \\
\hline Vaginal bleeding & 1.65 (1.26 to 2.16$)$ & 1.98 (1.56 to 2.51$)$ & Not retained \\
\hline Placental conditions & 1.70 (1.19 to 2.43$)$ & 1.65 (1.21 to 2.25$)$ & $1.39(1.02$ to 1.90$)$ \\
\hline Placenta abruption & 3.14 (2.15 to 4.57$)$ & 2.66 (1.91 to 3.72$)$ & Not retained \\
\hline \multicolumn{4}{|l|}{ Asthma-related variables } \\
\hline SABA (doses/week) & & Not retained & Not retained \\
\hline 0 & Reference & & \\
\hline$>0-3$ & 1.15 (0.90 to 1.47$) c$ & & \\
\hline$>3$ & $1.18(0.90$ to 1.55$) \mathrm{c}$ & & \\
\hline Severity of asthma prior to pregnancy & Not retained & & \\
\hline Mild & & Reference & Reference \\
\hline Moderate & & $0.88(0.68$ to 1.13$) \mathrm{c}$ & $1.05(0.85$ to 1.29$) \mathrm{c}$ \\
\hline Severe & & 0.71 (0.47 to 1.08$) \mathrm{c}$ & $1.29(0.96$ to 1.74$) \mathrm{c}$ \\
\hline
\end{tabular}

published randomised controlled trial. ${ }^{30}$ Powell et $a l^{30}$ looked at the fraction of exhaled nitric oxide (FeNO) versus symptomguided treatment of pregnant women with asthma in which the algorithms resulted in a greater frequency of exposure to ICSs (but lower dose) and LABAs in the FeNO group. In addition to the primary endpoint of moderate or severe exacerbations (reduced in the FeNO group), the authors also looked at fetal complications between the FeNO and symptom groups: intrauterine-growth restriction $(2.8 \%$ vs $0.95 \%)$, PB $(8.3 \%$ vs $5.7 \%)$ and LBW (5\% vs 5\%). These differences were not statistically significant, as expected with groups of 105 and 109 women. The use of low-dose ICSs with an earlier introduction of LABAs is consistent with recently published guidelines. ${ }^{3} 31$

Our study has some limitations that should be taken into account in interpreting the results. LABA exposure has some limits with an important number of women receiving only a month's supply of medication during the entire pregnancy, leading to an underestimation of the effect of these medications. There is some imprecision in the calculation of ICS exposure, especially for the $0-62.5 \mu \mathrm{g} /$ day category, which included varying patterns of use such as a single short course of highdose ICSs or even a single day of exposition. The higher ICS-dose categories are more accurate indicators of a continuous exposure. Prescriptions filled in community pharmacy, although not a direct measure of a woman's exposure, is considered a relevant proxy. Also, this possible misclassification of the exposure, if present, is likely to be non-differential and would usually lead to an underestimation of the true association. Women in the highest-ICS-dose categories were also more likely to be exposed to oral and nasal corticosteroids, resulting in a higher total exposure to corticosteroids. Some risk factors could not be controlled because of incomplete coding (ie, poor maternal nutrition, obesity, alcohol abuse and others) or complete absence (folic-acid deficiency) of the condition in the database. Information on smoking status would have been preferable to the indirect adjustment method. This method indicates that the measured OR could be an underestimation of the true OR by a factor of $6 \%$ at the most, a small difference due mainly to the 
similar smoking prevalences observed between users and non-users of ICSs in a similar previous cohort from our group. ${ }^{19}$ Assuming greater smoking in medication non-users 919 the observed OR, for all three outcomes, would be an overestimation of the potential benefit for LABA and an underestimation of the true risk for ICSs. The possibility of residual confounding by uncontrolled or more severe asthma as described above cannot be ruled out completely. Measures of symptoms or pulmonary function could have permitted a better adjustment for asthma control. Finally, there is a high proportion $(>50 \%)$ of women receiving social assistance in our cohort, limiting the generalisability of our results. The study's strengths are the large number of women exposed to ICSs and LABAs during pregnancy, medication-exposure assessment from data prospectively collected independently of the outcomes and recorded in pharmacy records (avoidance of recall bias), the inclusion of multiple potential confounders, and the use of previously validated algorithms to measure ICS and short-acting $\mathrm{B}_{2}$-agonists exposure, and control and severity of asthma. The retrospective study design is more reflective of standard medical care than a more intense prospective follow-up possibly resulting in fewer exacerbations, particularly in the more susceptible highest-ICS-dose groups. ${ }^{24}$

In summary, the data on LABA use is reassuring, especially in light of the possibility of residual confounding by uncontrolled or severe asthma or smoking status. Moreover, ICS doses $<125 \mu \mathrm{g} /$ day were not associated with increased prevalence of the perinatal outcomes. However, additional work is needed before we can rule on the safety of higher doses of ICSs. Despite the fact that it is scientifically relevant to disentangle the pharmacological effect of higher doses of ICS from the effect of residual confounding, in clinical practice, women treated with higher doses of ICSs may be at increased risk of having a small baby or a preterm delivery, and need more intense follow-up during pregnancy. The available data at the moment suggests that the benefits of LABAs or higher doses of ICSs to maintain asthma control would outweigh their potential risks of adverse maternal and fetal effects.

Acknowledgements We thank the Régie de l'assurance maladie du Québec and IRIS-Québec for assistance with the data. We are grateful to the Commission d'accès à l'information du Québec for authorising the study.

Contributors $L B, B C, A F, M-F B$ and $E R$ conceived and designed the study. $L B, B C$, $A F$ and $M-F B$ contributed to data analysis. $L B, B C, A F, M-F B, E R, C L, P L$ and $M-C B$ contributed to data interpretation. $L B, B C$ and $M-F B$ wrote the manuscript. $L B, B C$, $A F, M-F B, E R, C L, P L$ and $M-C B$ contributed to editing the manuscript. $L B$ acquired the funding.

Funding This study was funded through grants received from the Canadian Institutes of Health Research and IRIS-Québec. The supporting source had no involvement in study design; data collection, analysis, or interpretation; the writing of the report; or the decision to submit the report for publication.

Competing interests All authors have completed the Unified Competing Interests form at http://www.icmje.org/coi_disclosure.pdf (available on request from the corresponding author) and declare: $L B, B C$ had financial support for the submitted work from the Canadian Institutes of Health and Iris-Québec; BC has a doctoral training award from the Fonds de recherche du Québec - santé; LB has received research grants from Genentech; BC has received research grants from Novartis, Sanofi, Eli Lilly, NovoNordisk; M-FB has received research grants from GlaxoSmithKline, AstraZeneca, Sanofi, Eli Lilly and NovoNordisk; CL has been paid for delivering educational presentations for AstraZeneca; PL has been paid for delivering educational presentations for GlaxoSmithKline, AstraZeneca, Boehringer Ingelheim, Merck, Novartis; M-FB has received payment from GlaxoSmithKline and AstraZeneca for the development of educational presentations; $\mathrm{CL}$ does consultancy for AstraZeneca and GlaxoSmithKline; no other relationships or activities that could appear to have influenced the submitted work.

Ethics approval Approval was obtained from the Commission d'accès à l'information du Québec prior to requesting and linking the information from the
MED-ECHO and the Régie de l'assurance-maladie du Québec (RAMQ) databases. This study was approved by the ethics committees of Hôpital du Sacré-Coeur de Montréal and the Centre hospitalier universitaire de Sherbrooke.

Provenance and peer review Not commissioned; externally peer reviewed.

\section{REFERENCES}

1 Kwon HL, Triche EW, Belanger $\mathrm{K}$, et al. The epidemiology of asthma during pregnancy: prevalence, diagnosis, and symptoms. Immunol Allergy Clin North Am 2006;26:29-62.

2 Bakhireva LN, Schatz M, Jones KL, et al. Asthma control during pregnancy and the risk of preterm delivery or impaired fetal growth. Ann Allergy Asthma Immunol 2008; 101:137-43.

3 From the Global Strategy for Asthma Management and Prevention, Global Initiative for Asthma (GINA) 2011. http://www.ginasthma.org/ (accessed 21 Dec 2012).

4 Murphy VE, Clifton VL, Gibson PG. Asthma exacerbations during pregnancy: incidence and association with adverse pregnancy outcomes. Thorax 2006;61:169-76.

5 NAEPP expert panel report. Managing asthma during pregnancy: recommendations for pharmacologic treatment-2004 update. J Allergy Clin Immunol 2005; 115:34-46.

6 National Heart Lung and Blood Institute. Expert Panel Report 3: Guidelines for the Diagnosis and Management of Asthma (2007). http://www.nhlbi.nih.gov/guidelines/ asthma/ (accessed 29 Aug 2012).

7 Bracken MB, Triche EW, Belanger K, et al. Asthma symptoms, severity, and drug therapy: a prospective study of effects on 2205 pregnancies. Obstet Gynecol 2003; 102:739-52.

8 Clifton VL, Rennie N, Murphy VE, et al. Effect of inhaled glucocorticoid treatment on placental 11 beta-hydroxysteroid dehydrogenase type 2 activity and neonatal birthweight in pregnancies complicated by asthma. Aust N Z J Obstet Gynaecol 2006;46:136-40.

9 Alexander S, Dodds L, Armson BA. Perinatal outcomes in women with asthma during pregnancy. Obstet Gynecol 1998;92:435-40.

10 Bakhireva LN, Jones $\mathrm{KL}$, Schatz $\mathrm{M}$, et al. Asthma medication use in pregnancy and fetal growth. J Allergy Clin Immunol 2005;116:503-9.

11 Dombrowski MP, Schatz M, Wise R, et al. Randomized trial of inhaled beclomethasone dipropionate versus theophylline for moderate asthma during pregnancy. Am J Obstet Gynecol 2004;190:737-44.

12 Hodyl NA, Stark MJ, Osei-Kumah A, et al. Fetal glucocorticoid-regulated pathways are not affected by inhaled corticosteroid use for asthma during pregnancy. Am J Respir Crit Care Med 2011;183:716-22.

13 Hodyl NA, Wyper H, Osei-Kumah A, et al. Sex-specific associations between cortisol and birth weight in pregnancies complicated by asthma are not due to differential glucocorticoid receptor expression. Thorax 2010;65:677-83.

14 Namazy J, Schatz M, Long L, et al. Use of inhaled steroids by pregnant asthmatic women does not reduce intrauterine growth. J Allergy Clin Immunol 2004;113:427-32.

15 Schatz M, Dombrowski MP, Wise R, et al. The relationship of asthma medication use to perinatal outcomes. J Allergy Clin Immunol 2004;113:1040-5.

16 Schatz M, Zeiger RS, Harden K, et al. The safety of asthma and allergy medications during pregnancy. J Allergy Clin Immunol 1997;100:301-6.

17 Kramer MS, Platt RW, Wen SW, et al. A new and improved population-based Canadian reference for birth weight for gestational age. Pediatrics 2001;108:E35.

18 Lee PA, Chernausek SD, Hokken-Koelega ACS, et al. International Small for Gestational Age Advisory Board consensus development conference statement: management of short children born small for gestational age. Pediatrics 2003;111:1253-61.

19 Blais L, Beauchesne MF, Rey E, et al. Use of inhaled corticosteroids during the first trimester of pregnancy and the risk of congenital malformations among women with asthma. Thorax 2007:62:320-8.

20 Martel MJ, Rey E, Beauchesne MF, et al. Use of short-acting beta-agonists during pregnancy and the risk of pregnancy-induced hypertension. J Allergy Clin Immunol 2007;119:576-82.

21 Firoozi F, Lemiere $C$, Beauchesne $M-F$, et al. Development and validation of database indexes of asthma severity and control. Thorax 2007;62:581-7.

22 Schneeweiss S, Glynn RJ, Tsai EH, et al. Adjusting for unmeasured confounders in pharmacoepidemiologic claims data using external information: the example of COX2 inhibitors and myocardial infarction. Epidemiology 2005;16:17-24.

23 Institut de la statistique du Québec. Naissances selon la durée de la grossesse et le poids à la naissance, Québec, 1980-2009. http://www.stat.gouv.qc.ca/donstat/ societe/demographie/naisn deces/naissance/418.htm (accessed 29 Aug 2012).

24 Murphy VE, Namazy JA, Powell H, et al. A meta-analysis of adverse perinatal outcomes in women with asthma. BJOG 2011;118:1314-23.

25 Murphy VE, Zakar T, Smith R, et al. Reduced 11 beta-hydroxysteroid dehydrogenase type 2 activity is associated with decreased birth weight centile in pregnancies complicated by asthma. J Clin Endocrinol Metab 2002;87:1660-8. 


\section{Asthma}

26 Jana N, Vasishta K, Saha SC, et al. Effect of bronchial asthma on the course of pregnancy, labour and perinatal outcome. J Obstet Gynaecol 1995;21:227-32.

27 Firoozi F, Lemiere C, Ducharme FM, et al. Effect of maternal moderate to severe asthma on perinatal outcomes. Respir Med 2010;104:1278-87.

28 Firoozi $F$, Lemière $C$, Beauchesne $M-F$, et al. Impact of maternal asthma on perinatal outcomes: a two-stage sampling cohort study. Eur J Epidemiol 2012;27:205-14.
29 Bloom S, Sheffield J, Mclntire D, et al. Antenatal dexamethasone and decreased birth weight. Obstet Gynecol 2001;97:485-90.

30 Powell H, Murphy VE, Taylor DR, et al. Management of asthma in pregnancy guided by measurement of fraction of exhaled nitric oxide: a double-blind, randomised controlled trial. Lancet 2011;378:983-90.

31 Lougheed MD, Lemiere C, Ducharme FM, et al. Canadian Thoracic Society 2012 guideline update: diagnosis and management of asthma in preschoolers, children and adults. Can Respir J 2012;19:127-64. 